\title{
MARÍA ZAMBRANO Y LA CIUDAD ${ }^{1}$
}

\author{
RICARDO PINILLA BURGOS \\ Universidad Pontificia Comillas
}

\begin{abstract}
RESUMEN: Las sugerentes meditaciones de Zambrano sobre la ciudad se cotejan a la luz de otros escritos coetáneos sobre la casa; y no tanto porque la ciudad sea también arquitectura, sino porque es habitada y recorrida, porque presenta un orden a ser ejecutado, avivado desde el ritmo de nuestro ir, venir, nuestras estancias y nuestras ausencias; como la música. Para Zambrano la ciudad es paradigma y lugar idóneo de la creación humana a lo largo de la historia. Es el amor como entrega y fe el motor de toda creación que trasciende su propia época, y sólo desde ahí cabe una recuperación de la ciudad en nuestro presente, en el que sólo vivimos en grandes construcciones urbanísticas, pero en el que ya no surgen ciudades. Zambrano reivindica recuperar la ciudad como centro sacral y creador, pero no como una vuelta nostálgica a las ciudades del pasado, sino como verdadera realización de su ideal político democrático.
\end{abstract}

PALABRAS CLAVE: ciudad; casa; creación; amor; fe; democracia.

\section{María Zambrano and the city}

ABSTRACT: Zambrano's suggestive meditations on the city are compared with other contemporary writings on the house; and not so much because the city is also architecture, but because it is dwelled and walked, because it shows an order to be executed, enlivened from the rhythm of our going, coming, our stays and our absences; like the music. For Zambrano, the city is a paradigm and an ideal place for human creation throughout the History. Love as dedication and faith is the engine of all creation that transcends its own time, and only from there it could take place a recovery of the city in our present, where we only live in large urban constructions, nevertheless the cities don't already arise. Zambrano claims to recover the city as a sacred and creative center, however not as a nostalgic return to the cities of the past, but as true realization of her democratic political ideal.

KEY WORDS: city house; creation; love; faith; democracy.

\section{LAS CIUDADES RECORDADAS Y ENSOÑADAS}

Podríamos decir que las ciudades en las que vivió María Zambrano, pensemos en los diversos lugares y ciudades que la fueron acogiendo en su larga y azarosa vida de exilio, constituyen estaciones vitales que repercutieron sin duda en su intimidad creadora ${ }^{2}$. También los países, las naciones, los pueblos, los

1 Este artículo tiene su origen en una ponencia del mismo título presentada en las XIII Jornadas Internacionales de Hispanismo (Salamanca, 28 marzo-1 abril 2017). Agradezco de corazón a Jesús Moreno Sanz y Sebastián Fenoy la gran ayuda para la revisión y terminación de este texto.

2 Desde el Seminario María Zambrano, de la Universidad de Barcelona, se dedicó el primer número monográfico de la Revista Aurora al tema de la ciudad, por iniciativa de Sebastián Fenoy, guiado por el consejo de Jesús Moreno Sanz, y presentado por Carmen Revilla, con interesantes contribuciones para este tema, de la misma C. Revilla, S. Fenoy, Miguel Morey, Ana Bungard, y otros estudiosos de la obra zambraniana, incluyendo también textos de la misma filósofa: cfr. Aurora. Papeles del Seminario María Zambrano, núm. 2 1999; https://www.raco.cat/index.php/Aurora/issue/view/11624. Sobre el tema de la ciudad y sus 
paisajes, pero tal como reflejan algunos de sus escritos, fueron especialmente las ciudades las que formaron los diversos horizontes de su biografía (cfr. sus artículos sobre París o Roma ${ }^{3}$ ). En igual medida y acaso en primer lugar, han de considerarse las ciudades de su infancia y juventud, como Segovia y Madrid; esos años de formación, de estudio de la filosofía, de literatura y de activismo político. Cada una va contribuyendo a formar ese horizonte variable de presencias y ausencias que ya desde el temprano escrito "Ciudad ausente» (1928) nos habla de una relación íntima con el ámbito de la ciudad, también y especialmente cuando la ciudad desaparece en el horizonte para instalarse y amanecer con fuerza en el recuerdo, se diría que en la íntima ensoñación:

«Por eso tu verdad, ciudad, está en la ausencia de esta mañana —raso de aire- en que los ojos sin verte te sueñan $»^{4}$.

Sitúa aquí Zambrano esa ciudad ausente (Segovia), esa ciudad que se pierde en el horizonte, en el lugar de la amada o el amado, recordado y soñado. Si el amado se tiene presente, se trata con él, se disfruta y se sufre con él, éste va hilando parte esencial de nuestro recuerdo. En su ausencia recordamos su cuerpo, su ser concreto, pero también todo lo que constela en torno a su persona: su trayectoria, sus sueños, sus temores, sus límites. Se funde la vida de los amantes en sus recuerdos. Algo así de íntimo y profundo llegó a darse en la relación de Zambrano con las diversas ciudades de su vida. Creo que es desde esa posición del amor y del amante en soledad como cobran toda su fuerza las ideas que la pensadora malagueña expresa sobre la ciudad. En la selección de referencias y textos de M. Zambrano sobre el tema de la ciudad realizada por Sebastián Fenoy se muestra la relevancia e implicaciones de este tema junto a lo que Fenoy denomina «marco geográfico-vital $»^{5}$, esto es, los lugares, países e incluso continentes que la fueron acogiendo. Este asunto es abordado desde diversos ángulos si bien siempre en conexión con los centros medulares del pensamiento zambraniano. Con todo, los textos sobre la ciudad aparecidos en

implicaciones esenciales en toda la obra zambraniana, cfr. el informe: S. FenOy. «El tema de la ciudad o el marco-geográfico vital» en Aurora, núm 2, pp. 146-149; 144875-Text\%20de\%20 l'article-237803-1-10-20100420\%20(2).pdf En el núm. 3 de Aurora (2001) aparecían como complemento al número anterior, otros textos de Zambrano y referencias a manuscritos que resultarán centrales para el tema de la ciudad y la casa. Véase también: Zambrano, M., Obras Completas III, Edición dirigida por Jesús Moreno Sanz, Galaxia Gutenberg, Barcelona 2014, pp. 1363 y s., cfr. la nota 163, con un completo informe bibliográfico y en donde se citan también manuscritos inéditos, y en el que se afirma que la ciudad es un «tema capital en la escritura de la pensadora».

3 Zambrano, M., «Una ciudad: París», en: Lyceum, La Habana, 27 (1951), pp. 13-13; Roma, ciudad abierta y secreta (I) Diario 16. Culturas. Suplemento Semanal. Madrid. núm. 8, p. III (2 de junio de 1985); «Roma, ciudad abierta y secreta (II)» Diario 16. Culturas. Suplemento Semanal. Madrid, núm. 9 (9 de junio de 1985).

4 Zambrano, M., "Ciudad ausente», en: Aurora: papeles del Seminario María Zambrano, [en línea], 1999, Núm. 2, p. 133, https://www.raco.cat/index.php/Aurora/article/view/144870. Este texto aparecía originalmente en la revista Manantial, núm. 4 y 5, Segovia 1928, p. 16

5 Fenoy, S., «El tema de la ciudad o el marco-geográfico vital», loc. cit. 
1964 en la Revista portorriqueña Semana, junto con otros inéditos sobre sobre la casa y sus partes ${ }^{6}$, al parecer destinados también a esa revista, aportarán elementos clave que trataremos de exponer aquí.

En «La ciudad, creación histórica», el artículo que parece abrir la serie sobre la ciudad, leemos:

«Una ciudad es también una arquitectura, un hablar, unas tradiciones religiosas y profanas, unas costumbres, un estilo; un orbe entero que lo contiene todo; un sistema de vida. Un lugar privilegiado, una luz que le es propia, un paisaje» ${ }^{7}$.

Un paisaje, en definitiva. Esta última palabra no es quizá casual. Zambrano tiene presente seguramente la importancia de la idea de paisaje en pensadores españoles, como Miguel de Unamuno, o en la relevancia vivencial y pedagógica que el paisaje tuvo en la Institución Libre de Enseñanza. María Zambrano operaría ahora un giro urbano o metropolitano, si bien ni en los antecedentes mencionados se excluye el elemento humano e histórico del paisaje, ni ahora en la evocación zambraniana se olvidarán los elementos naturales. Lo que Zambrano nos invita a pensar en el citado pasaje es la misma ciudad como paisaje, esto es, como ámbito amplio y como horizonte en el que nos movemos y existimos, y que de alguna manera, llevaremos en nuestra alma allá donde quiera que vayamos, como ciudad ausente, recordada y añorada. Esa asunción de la ciudad como paisaje, como entorno que forma casi una segunda naturaleza, acerca quizá nuestra pensadora a la relación con la ciudad que se dio entre los poetas franceses de final del XIX, especialmente en figuras como Baudelaire. No vivimos tanto en un medio natural, sino en un paisaje urbano, desde el que también accedemos al entorno natural.

Sin embargo, no reivindica Zambrano expresamente la ciudad como el nuevo paisaje, en un sentido sustitutorio de la naturaleza, sino que plantea más bien la necesidad de habitar y vivir en la ciudad frente a la misma casa: «que no se vive en una casa, sino en una ciudad ${ }^{8}$, concluirá con contundencia. Esta afirmación en todo caso hay que ponerla en contexto. No se trata en absoluto de una crítica o desvaloración de la casa como lugar primordial del habitar,

6 Si en el número 2 de Aurora se reeditaban «Ciudad ausente» y el escrito sobre París, citados anteriormente, en el siguiente número aparecían: Zambrano, M., «La ciudad, creación histórica» (Semana, 22 abril de 1964); "La ciudad» (Semana, 11 de noviembre 1964); «La casa: El patio» (M-77 1964); «La casa y su melodía» (M-299, 12 de nov. De 1964): Aurora: papeles del Seminario de María Zambrano, núm. 3 (2001), pp. 140-144 (Citaré esta edición, indicando el título de cada escrito). Accesible en red: https://www.raco.cat/index.php/Aurora/ issue/view/11625. Zambrano redactó aún otros escritos sobre este tema en estos años: cfr. Zambrano, M., Obras Completas III, ed. cit. pp. 1363 s. Entre ellos tendremos también especialmente presente «Un lugar de la palabra: Segovia», aparecido en Papeles de Son Armadans, Palma de Mallorca, núm. 98, mayo de 1964, pp. 133-158; e incluido luego; en España, sueño y realidad (1965). Cfr. su reedición en: Zambrano, M., Obras Completas III, ed. cit. pp. 787 ss. También la nota 161: Ibid., p 1365.

7 Zambrano, M., «La ciudad, creación histórica», p. 140.

8 Ibid., p. 141. 
lugar donde es posible a la vez el refugio y la libertad, la intimidad y la apertura, tal como señalaría en su bello escrito sobre la casa mediterránea y su patio ${ }^{9}$. Más bien esa afirmación denuncia el olvido de la ciudad como lugar vivo y creador del habitar colectivo, precisamente en las ciudades modernas. Veamos el pasaje completo que concluye con la afirmación de que se vive en una ciudad, en la que se descubre una crítica de la ciudad moderna desde consideraciones de gran calado:

«La ciudad se modula entre el cielo y la tierra revelándose a los dos, poniéndolos en relación, conjugándolos. De ahí la tristeza de la mayor parte de las extensiones urbanísticas de hoy que son simples conglomerados donde el hombre se aloja, pero no puede albergarse. Pues que no se vive en una casa sino en una ciudad. Y esto: que el hombre viva en una ciudad ante todo y no solamente en una casa, parece ser que se haya olvidado ${ }^{10}$.

En este pasaje se plantea una función existencial de la ciudad, que va más allá de sus cometidos habituales de lo que consideramos una residencia o una protección y ubicación respecto a la naturaleza salvaje, como de alguna forma una lectura funcional nos llevaría a establecer, pero también rebasa, o más bien queda enriquecida, la visión puramente lírica y nostálgica en torno a las ciudades en las que se ha vivido. La ciudad asume un papel mediador, congregador, que pone en juego nada menos que el cielo y la tierra; esto es, la ciudad permite nuestro lugar y punto de vista respecto a la totalidad de lo que nos rodea. Esta función congregadora recuerda el célebre ejemplo del puente que Heidegger exponía en su conferencia «Construir habitar pensar» (1951). El puente no sólo pone en unión, sino que hace aflorar las orillas y el mismo río como elementos de un conjunto, como lugar y como espacio que hace posible el habitar, eso que, siguiendo la simbología empleada aquí por el pensador alemán, hacen los mortales entre el cielo, la tierra y los divinos; eso sí, residiendo entre las cosas ${ }^{11}$. Zambrano piensa esa función de congregación para la ciudad en su conjunto, como lugar desde el que sus habitantes se ubican y pueden abrirse al universo. No es sólo la casa y el hogar, sino la ciudad la que hace posible no sólo nuestra vida social sino nuestra misma identidad, esa ciudad de cada uno:

«La ciudad. Una ciudad, Una ciudad cualquiera. La de cada uno, pues (...) cada hombre tiene su ciudad, la suya propia e intransferible (...), ya que la ciudad es el lugar entre todos donde nuestra vida social y en ciertos aspectos cruciales íntima, crece y se expande» ${ }^{12}$.

Esa ciudad de cada uno es nuestra madre nutriente, allá donde hemos aprendido a ver el mundo, a hablar; es la matriz de nuestra vida y nuestra cosmovisión. Para subrayar la importante función existencial de la ciudad,

9 Zambrano, M., «La casa. El patio» loc. cit., p. 143.

10 Zambrano, M., «La ciudad, creación histórica», loc. cit., p. 141.

11 Véase respectivamente: HeidegGer, M., «Bauen Wohnen Denken», en: Vorträge und Aufsätze (Ges. Ausgabe 7), V. Klostermann, Frankfurt a.M., 2000, pp. 154 ss.; 152 ss.

12 Zambrano, M., «La ciudad», loc.cit., pp. $141 \mathrm{~s}$. 
alude nuestra pensadora a nociones filosóficas de gran calado como la idea de «cosmovisión» (Weltanschauung) de Dilthey, o a la de «lugar del hombre en el cosmos», que Max Scheler utilizó para su incipiente proyecto de una nueva Antropología filosófica ${ }^{13}$. Se diría no obstante que aquí Zambrano no quiere enfatizar tanto una suerte de ampliación urbana o metropolitana que sustituya al hogar como identidad matriz, sino que más bien reclama ese entorno vivencial para la ciudad, un entorno que no sólo es funcional o anónimamente colectivo, sino que apela a lo corporal y a la memoria íntima, a lo carnal, local y físico de lo que nos rodea y del ámbito en el que vivimos. La ciudad que nos ha visto nacer y crecer es nuestra verdadera patria y cuna de la identidad, nuestra «matria», si se quiere emplear la expresión usada por Unamuno frente a la idea de patria ${ }^{14}$. Esta inserción de lo maternal y lo femenino en la ciudad, de su capacidad de crianza de sus ciudadanos, nos permite ver cómo la idea de hogar como lugar de la forja de nuestra identidad más íntimas, lejos de quedar postergada, se abriría al plano colectivo y social. En una aguda expresión que asimila la pensadora malagueña la ciudad y su vida a una lengua materna, nos dice que esa nuestra ciudad nos ofrece «un lugar determinado: un lugar donde nos sentimos estar cobijados, un lugar donde las cosas y los seres nos hablan directamente en un lenguaje que con palabras o sin ellas, no nos vemos obligados a traducir. Y este lugar lo llevamos con nosotros» ${ }^{15}$.

Por todo esto, por esa connaturalidad que llega a adquirir nuestro lugar de origen, esa ciudad matriz no es un lugar exclusivamente geográfico; pues en esa sintonía íntima, vital y cosmovisional no existen los lugares meramente extensionales y localizables tal como los estudia la ciencia geográfica. En ese plano existen los lugares históricos, y dicho con independencia de que la ciudad tenga mucha o poca historia en sentido objetivo. La ciudad, aun detentora de elementos tan plásticos y texturales como se ha ido apuntando, se alza para Zambrano como una realidad que trasciende lo meramente extensional. La ciudad es un hecho, pero también una realidad espiritual, que vive en el tiempo recordado, en nuestra historia, y también es escenario de nuestros proyectos y deseos. Por eso, esa ciudad de cada uno la llevamos con nosotros. Es más, es cuando estamos alejados de ella, más aún en situaciones de expulsión o exilio, cuando «nos damos cuenta de lo que es nuestra ciudad para nosotros. Un día, cuando nos hemos alejado de ella...» ${ }^{16}$.

La dialéctica de la ausencia y la presencia, tan vinculada a la poética del recuerdo, se halla así profundamente ensamblada con ese cometido existencial de la ciudad que nos hace crecer y nos propicia una identidad y un lugar desde

13 Cfr. Zambrano, M., «La ciudad», loc. cit., p. 142; «La ciudad, creación histórica», loc cit., p. 141 .

${ }_{14}$ Véase el interesante artículo: Dobón AnTón, $M^{\mathrm{a}}$ D., «Matria contra patria en la trayectoria espiritual de Unamuno», en: Cuadernos de la Cátedra Miguel de Unamuno, 34 (1999), pp. $75-96$

15 Zambrano, M., La ciudad, loc. cit., p. 142; «La ciudad, creación histórica», loc cit., p. 142.

16 Ibid., 
donde entender y contemplar el universo. Es en la ausencia, es en la pérdida y lejanía de nuestra ciudad, quizá de otras ciudades que nos acogieron, cuando se hace nítido su valor existencial. Y qué cerca de la íntima biografía de María Zambrano está este pensamiento. Se diría que a lo largo de toda su vida, pero quizá de modo muy especial en esos años de comienzo de la década de los años sesenta, cuando escribió estos breves textos para una revista en Puerto Rico, lugar que recordaba con gran placer desde su estancia a comienzo de los años cuarenta; y lo recordaba desde Europa, inicialmente desde la ciudad eterna, Roma, que tendría que abandonar precisamente el 14 de septiembre de 1964, camino del que sería su lugar de residencia fuera de toda ciudad, en la solitaria casa de La Piéce, en el Jura francés ${ }^{17}$. Son sin duda atribuladas y también interesantes y reveladoras circunstancias para poner en contexto los escritos que ahora analizamos. Cabría preguntar, desde los mismos planeamientos de Zambrano, cuál es esa su ciudad madre nutriente. Seguramente habrá que apuntar a Segovia, esa dilatada «ciudad ausente» que evocaba ya en su juventud en Madrid. Pero encontraríamos también otras ciudades matriz, otros lugares que le abrieron al mundo, que forjaron y acogieron su intrahistoria y su trayectoria vital: Madrid, La Habana, San Juan de Puerto Rico, París, Roma... Creemos que una detección de esas cartografías dinámicas de presencias, ausencias, pérdidas, descubrimientos y reencuentros de Zambrano con sus ciudades y lugares aporta un eje de gran valor no sólo para la intelección de su vida y el contexto de creación y génesis de su obra, sino para ahondar en dimensiones de todo su pensamiento. Esta tarea desbordaría sin duda este breve escrito. De otro lado, hay claves fundamentales aún que exponer en las reflexiones zambranianas sobre la ciudad que merecen nuestra atención.

\section{Claves de la (Des)AParición de las ciudades: Historia, CReación, AMOR}

En las anteriores reflexiones hemos visto que Zambrano se distancia del urbanismo moderno, acaso por su carácter anónimo y deshumanizado. Esta crítica aparece en no pocos intelectuales y escritores del siglo XX, que vivieron grandes cambios en la configuración del entorno de las ciudades y en la misma construcción de las casas. Este sabroso pasaje de Bachelard, de 1957, en el que cita también al poeta Claudel y a Max Picard, nos aporta un testimonio valioso en este sentido:

«En París no hay casas. Los habitantes de la gran ciudad viven en cajas superpuestas: "Nuestro cuarto parisiense—dice Paul Claudel—, entre sus cuatro paredes, es una especie de lugar geométrico, un agujero convencional que amueblamos con estampas, cachivaches y armarios dentro de un armario" (Oiseau noir dans le soleil levant, p. 144). El número de la calle, la cifra del

17 Cotéjense con detalle estos datos biográficos en J. Moreno SAnz, María Zambrano. Minima biografía, Isla de Siltolá, Sevilla, 2019, pp. 72, 160 ss. 166. 
piso fijan la localización de nuestro "agujero convencional”, pero nuestra morada no tiene espacio en torno de ella ni verticalidad en sí. "Sobre el suelo las casas se fijan con el asfalto para no hundirse en la tierra." (Max Picard, Lafuite devant Dieu, p. 121). La casa no tiene raíces. Cosa inimaginable para un soñador de casas: los rascacielos no tienen sótano. Desde la acera hasta el techo, los cuartos se amontonan y el toldo de un cielo sin horizonte ciñe la ciudad entera. Los edificios no tienen en la ciudad más que una altura exterior. Los ascensores destruyen los heroísmos de la escalera. Ya no tiene ningún mérito vivir cerca del cielo» ${ }^{18}$.

En estas agudas críticas aparece el aspecto del anonimato, la estandarización (geométrica y cuantitativa) de la morada, vaciada de su identidad y su raíz y convertida en mera vivienda, quizá en esa «máquina de habitar», que el gran arquitecto Le Corbusier planteaba como solución racionalista al problema de la vivienda ya en los años veinte, ante los problemas sociales del incremento de población de las grandes ciudades y también ante la gran destrucción que había traído ya la Primera Guerra Mundial. No hay que olvidar que el movimiento moderno en arquitectura planteó este ideal frente a una vivienda tradicional precaria y de otro lado nunca apreciada como objeto fundamental de la gran arquitectura. El mismo Le Corbusier y los grandes arquitectos del movimiento moderno unían a sus soluciones pragmáticas ideales sociales y políticos y también confiaban en aportar una transformación espiritual y estética en la vida de los ciudadanos. El balance del movimiento moderno y su excesiva racionalización en seguida contó con voces críticas, como las del poeta Claudel, en la obra de 1927-29, que cita Bachelard. Progresivamente ha sido la misma arquitectura la que ha visto los problemas y consecuencias de estos planteamientos en exceso quizá racionales, funcionales y simplistas, sin demérito de su indudable aportación a lo largo del siglo $\mathrm{XX}^{19}$.

Ahora bien, la crítica de Zambrano se fijará en los textos aludidos más en la misma constitución y crecimiento de la ciudad ${ }^{20}$, no sólo en la factura de la vivienda moderna como tal, por eso veremos que más que la extinción de la casa, se denunciará una desaparición de las mismas ciudades en su sentido genuino. Para la comprensión en profundidad de esta operación, hemos de remontarnos

18 Bachelard, G., La poética del espacio, (trad. de E. Champourcín) F.C. E. México, 2000, pp. 44-45 [He subido al texto las referencia de las notas a pie de página].

19 Localizamos aquí uno de los debates principales de la teoría y la práctica de la arquitectura. Baste citar estos dos artículos recientes: Nuviala ANTELo, V., «Una casa es una máquina de habitar. Arquitectura del Movimiento Moderno como tecnología de los cuerpos» en: www.academia.edu/14701843/; GonZÁLEz, D. «La casa no es una máquina de habitar» en: Arquitectura y urbanismo, XXVIII, 1 (2007), pp. 55-57; cfr. también: PinILLA, R., «Vivienda, casa, hogar: Las contribuciones de la filosofía al problema del habitar», en: Documentación. Revista de Estudios Sociales y de Sociología Aplicada, núm 138: Vivienda y alojamiento (julioseptiembre 2005), pp. 13-39; especialmente pp. 26 ss.

20 En otros lugares acomete también Zambrano una crítica de la arquitectura moderna: cfr. infra nota 22 
con la misma filósofa a las bases y conceptos que sustentan toda acción humana y por ende la fundación y vida de la ciudad.

Para Zambrano el hombre hace historia cuando transciende los hechos, yendo más allá de ellos; y es ahí cuando acontece la creación, frente a la mera producción, la cual es consecuencia deducible o previsible a partir de los hechos antecedentes dados. Toda creación alberga también una parte de producción, pero va más allá: «Lo producido es ciertamente un resultado de una intención y aun de una voluntad pero es eso: un resultado en cierto modo previsto de una acción conjugada con las circunstancias. Mientras que la creación va más allá, añade algo nuevo, positivo, impensable un instante antes de que aparezca y que una vez aparecido se da a ver como esencial. Algo necesario y al par milagroso $»^{21}$.

Los hechos y circunstancias dadas pueden ser importantes y determinantes, pero la creación los transciende, y de alguna manera interrumpe la cadena consecuencial previsible a partir de ellos; es ahí donde aparece eso nuevo, un instante antes imprevisible, y una vez dado, imprescindible. Al hablar de la casa y nuestras acciones en ella, Zambrano la comparará especialmente con una interpretación de una partitura, como una melodía sobre una estructura, pero también alude a la relación de la acción de la palabra con la realidad, siendo esta pétrea e «impertérrita», y en cambio la palabra, aunque fije los hechos, siempre es fluida, aligera y dinamiza los hechos al nombrarlos: «la palabra penetra la realidad y la musicaliza $»^{22}$. No se trata de ignorar así los hechos, sino de redimirlos de su carácter petrificado y estatizante y en ello interviene lo más agudo del genio humano, su ubicación creadora en torno, y desde ahí se nos invita a pensar una sugerente idea de trascendencia asociada al acto creador; como aquello que supera y remueve los hechos, que, como en esa original imagen de la palabra, los dinamiza y los hace fluir, salvándolos de su rigidez pétrea.

Otro aspecto a no pasar por alto en la concepción zambraniana de la creación, frente a la mera producción, es su carácter imprevisto. Aquí nos hayamos muy cerca de la concepción artística de la poiseis, como algo más que una mera ejecución de un plan previo. La creación no es mera consecuencia de unas premisas, sino que rompiendo la cadena de las consecuencias instaura un nuevo orden en lo dado transformándolo. En el caso de la creación artística personal,

21 Zambrano, M., «La ciudad, creación histórica», loc. cit., p. 140.

22 Zambrano. M., «La casa y su melodía», loc. cit., p. 144. Jesús Moreno Sanz apunta reveladoramente cómo la meditación de la palabra en Zambrano, especialmente en su obra De la Aurora, es muy afín y nace de las mismas preocupaciones que esta meditación de la ciudad y la necesidad de reivindicar su carácter creador. La música, como razón musical, entrará aquí como alternativa a la razón arquitectónica, entendida como una construcción férrea y cerrada, lo que abrirá la consideración y crítica zambraniana de la arquitectura moderna: ZAMBRANo, M., Obras Completas III, ed. cit. [De la Aurora], pp. 207, 231, 334 ss; atiéndase a la nota 3 a esta obra: p. 820. Desborda los límites de este ensayo acometer la crítica zambraniana de la arquitectura moderna en su vinculación con esa confrontación de un modelo arquitectónico de pensamiento frente a uno poético y musical. Agradezco a J. Moreno las iluminadoras indicaciones a este respecto en una serie de conversaciones. 
este aspecto es comúnmente aceptado, pero lo original en el planteamiento de Zambrano es que lo plantea para una creación colectiva como la ciudad. Es más, es la ciudad el ejemplo paradigmático de toda la creación humana:

«Pocas cosas hay en la humana historia que tengan más carácter de creación que la ciudad. [...] La ciudad es lo más creador entre las estructuras de humana convivencia por serlo en sí mismo, y por haber sido a su vez el lugar donde las creación del espíritu humano se han dado» ${ }^{23}$.

Como ejemplo de ciudad que ha sido lugar de creación, señala nuestra itinerante filósofa la histórica ciudad de Florencia ${ }^{24}$ como cuna de grandes científicos, artistas y gobernantes. La ciudad es también un proyecto, por supuesto, pero su trazado unido a su historia propicia una serie de acciones, encuentros y trayectorias que hacen de ella una continua creación histórica; su arquitectura permite unos ritmos y unos usos que generan ese ámbito creador que capta la admiración de Zambrano. Esa situación de trascendencia de los hechos, de su dinamización y rebasamiento, más aún ese dislocamiento de toda intención o proyecto previo es lo que produce curiosamente lo perdurable. Esto es, lo que va más allá de su época. Lo que es simplemente producido en cambio «se extingue en un tiempo más o menos breve». La capacidad de perdurar de lo creado, de otro lado no es algo estático, sino que se erige como «fuente de creación ilimitada $»^{25}$.

En una línea conceptual clara que vincula la ciudad como obra genuinamente humana a lo creador, lo perdurable, lo que transciende y lo ilimitado, aúna Zambrano los aspectos arquitectónicos y concretos con los ecos históricos, y estos con los ritmos cotidianos y toda una estética de cadencias, voces y sonidos de la ciudad, contemplándola como obra de la convivencia y la acción grupal y colectiva a la vez que como testigo confidente de la intimidad de cada uno en la relación que forjamos con ella, sea con nuestra ciudad natal o con las ciudades que nos van acogiendo y formando. Desde todos estos aspectos plantea Zambrano una suerte de fisionómica de las ciudades, sobre todo de aquellas que como genuina creación propician y están abiertas a la creación de sus habitantes y generan ámbitos concretos de convivencia. Nada más lejos que la síntesis de todos los factores apuntados, como pudiera parecer, lleve a una especulación abstracta sobre la ciudad, que tuviera más que ver con su historia o los hechos acaecidos en ella pero no con su presente. Zambrano ve y contempla directa y plásticamente lo que podríamos llamar la forma o los rostros de las ciudades. Así hay ciudades horizontales, o verticales, y esto con independencia de sus dimensiones reales. Como ejemplo muy acertado en este sentido recuerda cómo un monumento en concreto puede otorgar una gran

23 Zambrano, M., «La ciudad, creación histórica», loc. cit., p. 140.

24 Además del conocimiento histórico y cultural, Zambrano había podido disfrutar de una estancia en esta bella ciudad en 1958, donde se encontró con su amigo el pintor Ramón Gaya: Moreno SAnz, J., Minima biografía, p. 144.

25 Zambrano. M., «La ciudad, creación histórica», loc. cit., p. 140. 
verticalidad en un ámbito arquitectónico principalmente horizontal, tal como sucede con la plaza del Cristo de los Faroles en la ciudad andaluza de Córdoba.

No tanto frente a la casa, reivindica Zambrano la ciudad frente a lo abstracto del Estado:

«La ciudad es lo que más se acerca a la persona, a ser a modo de una persona o al modo de la persona, en la vida histórica. Tiene figura, rostro, fisionomía, lo que el Estado se afana por tener. Es un espacio abierto e íntimo donde quien en él habita se siente al par fuera y dentro. Mientras que en el ámbito estatal el ciudadano se siente en un espacio homogéneo, como a la intemperie. La ciudad, frente al Estado, resulta ser un espacio cualitativo, sacralizado. En ella, y a través de ella, se verifica la comunión con los que fueron y que dejaron su nombre y la impronta en sus vivir diario. Es como un receptáculo del trascender que mana de un vivir propiamente humano» ${ }^{26}$.

Con la articulación de todas estas ideas, volvemos con más luz sobre esa función existencial y cosmológica que Zambrano apuntaba para la ciudad, como moduladora entre el cielo y la tierra, como sistema de vida, y desde aquí planteamos de nuevo su decepción o alarma respecto al urbanismo moderno y a las partes nuevas y extensiones de las ciudades, que llega a caracterizar como una «pérdida de fe en la ciudad». Las nuevas ciudades estarán quizá sólidamente construidas, esto es, "producidas», pero adolecerían de esa virtud creadora, y de ahí podríamos explicitar muchas otras circunstancias, enunciando de modo negativo todo lo demás que la ciudad implica o debería implicar: se daría un cierto cierre vital a la creación, una inmersión en lo efímero e inconsistente, y sobre todo una disgregación y desorientación existencial, una pérdida de sentido en relación con lo que nos rodea, con nuestro pasado y con nuestro porvenir. Nos insertaríamos en un mundo frio de intenciones y proyectos que buscarían un cumplimiento sin que nada inesperado o milagroso pudiera acontecer; la existencia estaría aparentemente cumplida, pero en realidad estaría petrificada, se diría muerta.

En lugar de hacer tan explícitos estos males, Zambrano nos levanta una última y fundamental carta de la constelación de nociones que está manejando para ahondar en la ciudad. Esa clave no es otra que el amor y la fe, que nos la descubre cuando afirma que «(t)odo lo que es creación humana hunde en el amor y en la fe sus raíces» ${ }^{27}$. Ahora cobra toda su fuerza la expresión "pérdida de fe en la ciudad», que quizá hay que entender como pérdida de fe en la ciudad como una creación viva, capaz de propiciar lo perdurable y de abrir a una nueva creación. Esta idea de creación vinculada al amor nos recuerda al ideal platónico. Tal como se describe en el Banquete, el amante en su acción disfruta de la belleza del amado y su amor le lleva a engendrar o crear en la belleza ${ }^{28}$. El amor es contemplación y acción creadora, admiración y recogimiento. Si desde

26 Zambrano, M., España, sueño y realidad [«Un lugar de la palabra. Segovia»], en: ZAMBRANo. M., Obras Completas III, ed. cit., pp. 787 s.

27 Zambrano. M.,"La ciudad, creación histórica", loc. cit., p. 141.

28 Platón, Banquete, 208d ss. 
estas claves preguntamos por ese olvido de la ciudad, la respuesta no se hace esperar: ese olvido habla de una falta de amor, y de ahí, de un desencanto y un descreimiento, de una pérdida de fe; de fe en la misma acción humana, no tanto en su eficacia, sino en lo que tiene de inesperado, esperanzador y milagroso, de hacer desde el amor o de acción amorosa. La ciudad moderna se tornaría así en la evidencia de la pérdida de la trascendencia en la cultura contemporánea, de la pérdida del ideal del amor platónico, ideal que Zambrano valoraba como unión necesaria de las grandes dimensiones humanas: la poesía, la religión y la filosofía ${ }^{29}$.

Lo interesante de esta reivindicación del amor y la fe, de ese ideal creador platónico, es que aquí se enuncia para esa creación colectiva y de alguna forma meta-individual que es la ciudad. La ciudad es creación abierta y se podría decir que acontece como tal en cada nuevo paso que damos en ella. La ciudad también es una creación constante en el tiempo, configurada históricamente por cada época y por cada uno de los que la habitan y transitan por ella. En su identidad confluyen lo material, lo espacial y lo arquitectónico con lo intangible de las tradiciones y creencias de los ciudadanos, también sus diferentes acciones cotidianas, su estilo de vida... hasta el mismo ruido y sonido de los acentos y rumores que pueblan las calles:

«Y también es la ciudad un rumor que resuena por plazas y calles, unos silencios que se estabilizan en lugares donde nada puede romperlos, un tono en las voces de sus habitantes y una especial cadencia en su hablar, una altura en los edificios y un modo de estar plantada el lugar que le es propio ${ }^{30}$.

Es destacable en este pasaje la apelación al mundo sonoro y musical. Estos elementos se emparentan directamente con el escrito de «La casa y su melodía». Zambrano aclara en él que "la música de una casa» a la que se quiere referir no es la música como tal que sus habitantes pueden escuchar o ejecutar, sino «la música que una casa por sí misma, en sí misma, tiene» ${ }^{31}$. Con el desarrollo de esta metáfora musical de los espacios habitados, Zambrano da una vez más muestra de su profunda y sutil concepción de lo musical, que no se atiene únicamente a lo que llamamos música de modo explícito. Como un verdadero músico, Zambrano es capaz de percibir ritmos, tonos, cadencias y modulaciones en lo que le rodea. No hemos de asumir que las analogías o metáforas que emplea nuestra filósofa son simple figuración retórica, sino que, igual que en relación con la noción de amor y de fe, en este caso Zambrano ve y vive, escucha y se deja mecer por la música de la casa. La construcción como tal de la casa sería un orden, una estructura, que compara con la partitura, y

29 Recordemos el análisis y valoración de María Zambrano de la «salvación» del amor para la filosofía operada por Platón, siendo que para nuestra pensadora: «En el amor está la cuestión verdadera»: Zambrano, M., Filosofía y poesía, F.C.E. Madrid 1987, p. 61; cfr. también 62 y ss.

30 Zambrano. M., «La ciudad, creación histórica», loc. cit., p. 141.

31 Zambrano, M., «La casa y su melodía», loc. cit., p. 143 
en parte podríamos añadir que marca un cierto marco armónico o tesitura. Y serán los habitantes los que lo quieran o no pondrán en pie y harán «sonar» y vibrar la casa:

«Depende esta música en gran parte de sus moradores, de sus idas y venidas, y del ritmo que ellas tangan, del tono y el timbre de las voces humanas que en ella resuenen y hasta del ladrido de los perros, del canto de los pájaros y del ronroneo del gato. Depende sobre todo del orden con que se vayan cumpliendo los actos de la vida cotidiana (...). Mas resulta que ello depende a su vez de la casa misma» ${ }^{32}$.

Esta declaración final habla de una enigmática pero patente complicidad dinámica entre el orden y el ritmo o ejecución de ese orden. Una complicidad así se da entre la casa y sus moradores y también podemos extender la analogía entre la ciudad y sus ciudadanos. No cabría decir si esos ritmos son consecuencias o causas de la estructura y personalidad de la casa y de la ciudad. Claro que existe antes físicamente una estructura construida, pero eso sólo es el comienzo de una profunda relación creativa y creadora de eso que acabamos llamando un hogar o una ciudad, con su identidad y su historia, que es capaz de ser receptáculo de nuevas trayectorias y de nuevos proyectos.

Hay sin lugar a dudas un gran componente lírico e íntimo en la visión zambraniana de la ciudad, pero creo que no por ello está alejada esta concepción de la realidad histórica, social y especialmente de la experiencia cotidiana y personal de lo que constituye una ciudad como una creación histórica y como un ámbito fundamental de la vida humana. Una ciudad en efecto no es la suma de sus arquitecturas y trazados urbanísticos; y tampoco es un documento social de sus habitantes en cada momento. Todos estos elementos se entrelazan en diversos tiempos, espacios, ritmos y sentidos en donde se van insertando nuevos sucesos, unos proyectados, otros imprevistos; unos construidos o destruidos físicamente, otros resignificados simbólicamente. Es a todas luces una miopía querer reducir una ciudad a un proyecto o contemplarla como un producto cerrado. Quizás las siguientes palabras del antropólogo C. Lévi-Strauss sobre la ciudad, motivadas por las grandes urbes que conoció en sus viajes, puedan complementar muy bien lo que valora Zambrano en la ciudad, y arrojan luz sobre la analogía de la ciudad como una creación artística en sí misma:

«Las grandes manifestaciones de la vida social tienen en común con la obra de arte el hecho de nacer al nivel de la vida inconsciente; porque si bien en el primer caso son colectivas y en el segundo individuales, la diferencia es secundaria, y hasta aparente, pues las unas son producidas por el público y las otras para el público, y ese público proporciona a ambas su común denominador y determina las condiciones de su creación.

Por lo tanto, y no sólo metafóricamente, tenemos el derecho de comparar, como tan a menudo se ha hecho, una ciudad con una sinfonía o con un poema: son objetos de la misma naturaleza. Quizá más preciosa aún,

$32 \quad$ Ibid., p. 144. 
la ciudad se sitúa en la confluencia de la naturaleza y del artificio. Congregación de animales que encierran su historia biológica en sus límites y que al mismo tiempo la modelan con todas sus intenciones de seres pensantes, la ciudad, por su génesis y por su forma, depende simultáneamente de la procreación biológica, de la evolución orgánica y de la creación estética. Es a la vez objeto de naturaleza y sujeto de cultura; es individuo y grupo, es vivida e imaginada: la cosa humana por excelencia» ${ }^{33}$.

Creemos que Zambrano suscribiría de buen grado estas palabras, también esa alusión a la dimensión inconsciente, que en el planteamiento de la filósofa malagueña se torna escucha y atención a lo inesperado. En todo caso el planteamiento zambraniano articula elementos fundamentales más allá de la admiración ante una obra colectiva en la que confluyen elementos fundamentales de la naturaleza y la cultura. Zambrano incide de modo característico en esa línea de amor; amor y fe en el mismo hecho de la creación que permite trascender lo momentáneo y aportar una visión del mundo y un sistema de vida. Este elemento cosmovisional no obstante tiene un componente de posibilidad y comporta como tal también un riesgo de malograrse, y por eso en el planteamiento de la filósofa se da una clara crítica y posicionamiento ante esa pérdida en las ciudades actuales.

Volvemos ahora sobre la crítica zambraniana al urbanismo moderno y a ese olvido y ausencia de la ciudad, a pesar de la gran proliferación de grandes urbes. La ciudad quedaría reducida a sus casas y a sus diversos espacios funcionales, pero tendería a desaparecer como creación colectiva viva y como ámbito de creación. Cabría aquí una discusión o refutación de estas afirmaciones, que acaso llevamos a cierto extremo a partir de ese olvido de la ciudad, esto es, del olvido de que el hombre vive en una ciudad y no solamente en una casa $^{34}$. Cabría también afrontar la argumentación de esta denuncia desde explicaciones arquitectónicas y urbanísticas concretas, y sin duda sería una línea a desarrollar. Pero Zambrano se dirige a lo esencial y propiamente filosófico de ese olvido y de esa ausencia de la ciudad, a pesar de la ingente construcción inmobiliaria de todo el siglo XX: «Raramente hoy surgen ciudades: lo que se edifica son extensiones urbanas, urbanizaciones». La explicación de esta ausencia y olvidos paradójicos de la ciudad en un mundo hiper-construido no deja lugar a dudas:

«que el hombre viva en una ciudad ante todo y no solamente en una casa parece ser que se ha olvidado. [...] No es propiamente la memoria lo que habría que explicar, es el olvido lo que pide ser explicado, como sucede con el amor. Y todo viene a ser amor, fe. Todo lo que es creación humana hunde en el amor y la fe sus raíces ${ }^{35}$.

33 Lévi-Strauss, C., Tristes trópicos, Eudeba, Buenos Aires 1976, p. 109.

34 Zambrano M., «La ciudad, creación histórica», loc. cit., p. 141.

35 Ibid. (el subrayado es mío). 
Creación, amor y fe quedan así íntimamente implicados en la posibilidad de toda obra y creación humana, al menos la destinada a conformar su vida y perdurar, y no es otro el plano trascedente y crucial en el que Zambrano ubica la ciudad como obra humana. Cabe pensar que ante la ausencia o disfunción de estos elementos en el tejido urbano, los ciudadanos sufren una suerte de destierro a pesar de vivir en grandes urbes, un destierro de carácter espiritual y antropológico íntimo, que afecta a su condición creativa y a su misma humanidad, al modo quizá de esa sociología de las muchedumbres solitarias de las que hablaría David Riesmann en su célebre estudio de $1950^{36}$. Esta crisis de la ciudad sin embargo no sólo nos descubre habitantes pasivos, sino faltos de fe y de amor, despojados de su condición creadora.

Es desde el amor y la fe desde donde hay que entender el acto primigenio del trazado de las ciudades desde la antigüedad, a partir de esa cruz inicial semejante a la construcción de un templo desde donde los hombres han hecho germinar sus emplazamientos, esa encrucijada que busca una orientación que dirima y ubique en la inmensidad del espacio y el cosmos, en el sentido en el que Mircea Eliade hablaba de la fundación del templo ${ }^{37}$; un lugar no sólo donde sobrevivir y hacer frente a adversidades, naturales o provocadas por otros grupos humanos, sino desde donde mirar y contemplar el universo. Zambrano apela explícitamente a la analogía de la ciudad en la Antigüedad con el templo y con el espacio sagrado:

«Era la ciudad ante todo un templo. Pues [...] templo es el lugar donde el hombre por el sólo hecho de estar en él, se siente entre el cielo y la tierra, en su sitio: en el lugar del hombre en el cosmos [...] Un lugar donde el hombre, conservando su soledad está en comunicación y en compañía. Que sin la soledad y la compañía el hombre está desquiciado. Y ahora en las extensiones urbanas, producto [...] desde luego de una laudable voluntad de dar a los hombres un alojamiento sano y confortable, el hombre se siente no solo, sino aislado. Le falta el centro, el sentirse ser miembro de una ciudad que tiene una función creadora ${ }^{38}$.

Contiene esta reflexión una finura antropológica que no hay que pasar por alto: la condición humana requiere de un centro desde el que relacionarse con el entorno y con los demás, un centro que permita la soledad y la compañía, no el aislamiento o la asfixia de la muchedumbre o de lo homogéneo. Y la fundación de ese lugar humano en la que está implicada su conformación y relación con el espacio es un acto sagrado, cercano a lo más esencial de todo acto religioso. Hoy la ciudad ya no sería sagrada y habría perdido sus límites y su centro, su capacidad de ubicarnos y de propiciarnos esa soledad y esa compañía. La construcción urbanística es «simplemente» útil, atiende a nuestras necesidades, pero no nos ubica, no aporta ese ámbito creador. El urbanismo

36 Riesmann, D. en colaboración con Reuel Denney y Nathan Glazer, The Lonely Crowd: A Study of the Changing American Character, Yale university Press, New Haven, 1950.

37 Eliade, M., Lo sagrado y lo profano, Guadarrama, Madrid 1967, pp. 32 ss.

38 Zambrano M., «La ciudad, creación histórica», loc. cit., p. 141. 
moderno seguramente en esa buena voluntad que no deja de reconocer Zambrano, se apresuró en descomponer la vida de los hombres en sus necesidades de cobijo, organización, comunicación, etc. pero olvidó quizá que el hombre es algo más que un ser que sobrevive, o que recibe cumplido desde su equipo instintual el programa de su existencia.

Aunque no encontramos concreciones explicitas sobre aspectos urbanísticos, nos puede iluminar la valoración que María Zambrano hizo del patio de la casa mediterránea. El patio es el centro de la casa en todos los sentidos, el que modula el espacio de libertad íntima, representado por las alcobas y las habitaciones y el «espacio ilimitado exterior ${ }^{39}$. Es un lugar donde se encuentran los propios de la casa con los ajenos, un lugar de encuentro, que preserva la libertad, pues en su carácter cerrado se abre al cielo y a la luz del día. Las analogías con el templo y con el ágora están presentes en su análisis de esta pieza de la casa. Más allá de que en las casas actuales no existen normalmente espacios así, y esto nos llevaría a una revisión de la arquitectura de la vivienda, cabe preguntarnos si las ciudades modernas preservan esos patios y esas ágoras. Parece que la última arquitectura sí ha tomado nota de la importancia de estos lugares de encuentro sin una función concreta, pero sabemos que el funcionalismo y el racionalismo en su factura más dominante cuestionaron estos espacios al menos en su realidad funcional indefinida. Así, Le Corbusier en la célebre Carta de Atenas, separaba los espacios de ocio de los de comunicación y los lugares de trabajo. Aspiraba a una organización funcional de la vida urbana que haría innecesaria la intersección de funciones en un mismo espacio, así aunque no suprime las plazas, que quedarían en su ideal convertidas en zonas verdes de ocio, y nada más, sí apunta a cierta supresión de la calle como lugar de encuentro y donde, por decirlo así, todo puede ocurrir y se de una conexión con las viviendas y su vida interior, como en una ciudad tradicional. Expresamente en el citado documento se prohíbe la «alineación de las viviendas a lo largo de las vías de comunicación ${ }^{40}$; en esta línea la ciudad moderna se concibe desde el concepto racional de la zonificación, esto es, separación de zonas según el tipo de función que habrían de aportar: habitar, circular, trabajar, recrear (ocio). Parece claro que la ciudad tradicional nunca separó sino más bien comunicó estas funciones, y propició espacios ambiguos como la calle, la plaza y otros lugares que implicaban estas y otras dimensiones de la vida en la ciudad. Las intenciones sociales y políticas de los grandes urbanistas y arquitectos del movimiento moderno estaban sustentadas en una impecable voluntad de mejora y progreso, pero faltó quizá una revisión antropológica más sutil y más profunda

39 Zambrano, M., «La casa: El patio», loc. cit. p. 143.

40 Le Corbusier, Principios de urbanismo (La Carta de Antenas). Discurso preliminar de Jean Girardoux, Ariel, Madrid 1971, p. 144. Aunque La Carta de Atenas, célebre manifiesto del urbanismo moderno, fue publicada por Le Corbusier y J L. Sert en 1942, esta tesis junto a otras respecto a la zonificación funcional de la ciudad ya se exponen en el VI Congreso Internacional de Arquitectura Moderna, celebrado en 1933. 
sobre la vida humana, su dimensión creadora y trascendente y su resistencia a ser factorializada en un número determinado de funciones.

Zambrano atisbó con gran agudeza estos problemas y seguramente su concepción de la condición humana desde la razón poética podría y aún puede aportar mucho a una crítica actual del urbanismo, si bien su reflexión no sólo se dirige a los técnicos y artífices de las ciudades, sino a cada uno de sus habitantes, para lo que urge una nueva refundación y una recuperación de la ciudad; tarea que no es sólo una cuestión técnica, sino vital y en un profundo sentido, política.

\section{RECUPERAR LA CIUDAD COMO CENTRO SAGRADO SIN SUS SOMBRAS DE EXCLUSIÓN: REALIZAR LA DEMOCRACIA}

Zambrano habla de las ciudades antiguas, especialmente de las ciudades mediterráneas que trazaban una cruz como estructura, de las murallas como límite del ámbito urbano. En ellas se daba un proceder religioso que centraba y organizaba la existencia ¿Nos encontramos ante una declaración nostálgica de esas ciudades del pasado que hoy aún forman los casos antiguos de las grandes ciudades europeas? Zambrano niega explícitamente que su planteamiento lleve a proponer una vuelta a ese tipo de ciudad, y su negativa no obedece tanto a razones arquitectónicas o funcionales, sino a razones políticas, pues no desconoce que esas ciudades surgieron también en parte desde actos sacrificiales de exclusión, de opresión, crueldad y de abusos de poder e injusticias:

«... espero que no entienda el lector que esto quiere decir que haya que implantar obligatoriamente el culto a una determinada confesión religiosa; que haya que renunciar al bien superno del respeto a las diferencias de confesiones religiosas y naturalmente, de razas ${ }^{41}$.

La ciudad antigua, con su potencia creadora, no dejaba de poseer grandes lacras desde el punto de vista moral y político: «En aquellas maravillosas ciudades había barrios inmundos, gentes condenadas de por vida a la humillación, al hambre; injusticia; esclavos en una u otra forma $»^{42}$. Zambrano no ve posible renunciar al avance político y social innegable de la modernidad en materia de igualdad, dignidad y respeto. Se detecta aquí un importante conflicto entre esa añoranza de la ciudad y las consecuciones de la modernidad. Quizá ambas cosas deben aflorar en sus contradicciones.

De un lado se detecta la paradoja de esas maravillosas y entrañables ciudades erigidas sobre una cara oculta de injusticias; de otro no se deja de contemplar el reverso de una modernidad que ha logrado una mayor atención a la igualdad y a la dignidad de todas las personas con independencia de su

41 Zambrano M., «La ciudad, creación histórica», loc. cit., p. 141.

42 Ibid. 
condición a cambio quizá de sumir la hombre moderno en el anonimato de la masa y de una existencia plana y unidimensional. Pero Zambrano no se quiere doblegar ante la escalofriante paradoja o contradicción inevitable de que todo documento de cultura esconde a la vez un documento de barbarie, tal como reza una célebre aserción de Walter Benjamin ${ }^{43}$. Y aquí nos sorprende Zambrano con un giro muy propio de su más íntimo pensamiento político cuando afirma taxativa: «No, la cuestión no es renegar de la "democracia", sino cumplirla» ${ }^{44}$.

Realizar los ideales de la democracia y de la política basada en los ideales de la Ilustración tendrá que implicar, asumiendo este planteamiento, unos elementos que tal vez no sean meramente pragmáticos o racionales. Zambrano no propone naturalmente ninguna vuelta de credos religiosos que sean excluyentes, ni plantea una recuperación de ciudades cerradas o protectoras de sus ciudadanos frente al resto, sino que aboga por una ciudad desde la democracia, desde la sensibilidad conseguida en la modernidad y su lucha por la igualdad y la dignidad de todos. Conseguir que renazca esa ciudad como creación no es una síntesis fácil; haciendo gala de un pensamiento profundo de la democracia, dice que lo que hay que hacer es cumplirla. Recordemos que, más allá de su uso gastado o su misma etimología, para Zambrano la democracia podría definirse como «la sociedad en la cual, no sólo es permitido, sino exigido, el ser persona» ${ }^{45}$. Esa nueva ciudad debería propiciar que todos sus habitantes, también todos sus visitantes, hubieran asumido su dignidad personal como algo inalienable en todo momento.

Con la alusión ahora a un cumplimiento de la democracia en lo que sería el resurgimiento de la ciudad como ámbito creador, apela Zambrano a una original unión de los ideales liberales y sociales con sus ideales estéticos, místicos y religiosos, y detectamos en esto un sello muy interesante de todo el pensamiento zambraniano que nos ayuda a encarar la modernidad y nuestras vidas, acaso en pos de esa «religión no sacrificial» que Jesús Moreno Sanz detecta como un horizonte de todo el pensamiento de Zambrano ${ }^{46}$. Para ello la ciudad se revela como lugar idóneo de esa realización creadora y renovadora sin fisuras de los ideales humanos en todas sus dimensiones. Habrá que crear nuevas ciudades, no meramente producir lugares para la convivencia, aunque esta pueda ser digna y eficaz. Más allá de todo pragmatismo, se apela a una convivencia sin necesidad de sombras ni exclusiones:

«crear centros, ciudades verdaderas, Ciudades nuevas ciertamente, donde resplandezca un orden, una armonía, en cuyas entrañas no se esconda la miseria y la humillación; donde no haya palacios en cuyas mazmorras giman los

43 «Jamás se da un documento de cultura sin que lo sea a la vez de la barbarie»: BENJAmIN, W., Discursos interrumpidos I, [Tesis sobre Filosofía de la Historia, VII], Prólogo, trad. y notas de Jesús Aguirre, Taurus, Madrid, 1973, p. 182.

44 Zambrano M., «La ciudad, creación histórica», loc. cit., p. 141.

45 Zambrano, M., Obras Completas III, ed. cit., [Persona y democracia], p. 474.

46 Zambrano, Obras Completas IV 1, edición dirigida por Jesús Moreno Sanz, Galaxia Gutenberg, Barcelona 2018, p. 821 (nota 7 a De la Aurora). 
condenados bajo el rumos de la fiesta; donde no haya lugares donde bárbaramente con procedimientos asépticos, se de la muerte y se torture. Si, puede parecer un sueño. Pero sueños han movido en parte la humana historia. El caso es soñar bien; soñar con la conciencia despierta ${ }^{47}$.

Se habrán de leer estas hermosas palabras y este contundente final del escrito «La ciudad, creación histórica», como algo más que un desmarque utópico; como una apuesta que podría ser irrealizable, casi irresponsable o frívola. La apelación al sueño, a ese sueño consciente y despierto, a un ethos audaz y responsable del soñar, incide muy directamente en la comprensión en su entraña más íntima de la razón poética y su implicación antropológica y política como sueño creador, como despertar en sí mismo ${ }^{48}$. Crear, nos lo ha dejado claro Zambrano en estos breves escritos, es ir más allá de todo lo dado, más allá incluso de lo posible. Y ese acto creador no deberá buscar otra fuente ni otra raíz que el amor y la fe. Cuando estos elementos faltan, la creación degenera en cumplimiento de un proyecto, y la acción humana se achata como producción, destinada a servir sin duda, pero no a perdurar ni en el tiempo ni en el alma de la comunidad. Cabría indicar que la barbarie, en el sentido benjaminiano de reverso inevitable de todo documento de cultura, podría interpretarse desde el planteamiento de nuestra pensadora como el índice de una creación y un amor todavía no realizados; una unidad que para ser tal ha de dejar versos sueltos, excluidos y víctimas. La atención a todo eso que queda como reverso de barbarie en la cultura, ha de incluirse, pero no en un plano gris de mera eficacia en la convivencia, en la que a la postre los convivientes sólo encontrarían a lo sumo en el hogar, en su casa, ese centro ya perdido y amortiguado, desposeído ya de la comunidad y de todo núcleo sagrado en su ciudad. El afuera se ha desacralizado para poder ser políticamente aceptable, pero una inclusión sin centro nos deja a todos descentrados, todos somos ya de alguna forma extranjeros en nuestra propia ciudad.

Ese sueño creador de nuevas ciudades habrá de salir de la misma mano de los artífices de la ciudad, los políticos, los urbanistas y sin duda los arquitectos $^{49}$, pero también y acaso primeramente, será tarea de cada uno de nosotros

47 Zambrano M., «La ciudad, creación histórica», loc. cit., p. 141.

48 «Soñar es ya despertar. Y por ello hay un soñar que despierta la realidad aún dormida en los confines de la vigilia»: Zambrano, M., Obras Completas III. ed.cit. [El sueño creador], p. 1014. Véase en esta misma obra el capítulo sobre «La legitimidad política del soñar»: Ibid., pp. 1041 ss.

49 Junto a la arquitectura, habría que señalar aquí en un lugar importante esa estirpe de grandes escultores de después de la Segunda Guerra Mundial, desde H. Moore hasta E. Chillida, y hoy Richard Serra, que tanto han contribuido a redefinir artísticamente el espacio urbano y el mismo entorno natural como un lugar de encuentro. En la arquitectura moderna habría que apuntar a exponentes clave como Frank Lloyd Wright, singular coetáneo del nacimiento del movimiento moderno, y la denominada «arquitectura del lugar» que encontrará su desarrollo más fecundo en la segunda generación de ese movimiento con figuras como Alvar Aalto. Entre los arquitectos actuales, cabe señalar a Álvaro Siza como ejemplo señero en esta línea. De su ingente obra destacaríamos aquí, en tanto que acción urbanística en sí 
en nuestra relación con el entorno. Deberemos reaprender a soñar despiertos en nuestros entornos urbanos, soñar y hacer nuestra la ciudad y re-habitarla en cada uno de sus ámbitos. No sólo haciendo uso de ella, sino reviviéndola como lugar de nuestros deseos, nuestra confianza y nuestro amor. Habitar creadoramente, interpretar y dotar de nuevas curvas melódicas e inéditas cadencias las estructuras ya construidas será una tarea común siempre pendiente, urgente por esencial, y seguramente fascinante.

Universidad Pontificia Comillas, Madrid

Departamento de Filosofía y Humanidades

Ricardo Pinilla Burgos pinilla@comillas.edu

[Artículo aprobado para publicación en febrero de 2020] $]^{50}$

misma, su reconstrucción del Chiado en Lisboa, destruido en el incendio acaecido el 25 de agosto de 1988. Cfr. Siza, A., Imaginar a evidencia, Edicôes 70, Lisboa 1998, p. 87; Pessanha VIEGAS, V. M., «El Chiado, una cuidadosa recuperación» en: Revista Urbanismo COAM, núm. 26 (Octubre 1997), pp. 36-47. Hoy día asistimos a una importante revisión de la idea de ciudad a la vista de cuestiones de inclusión social y de la cuestión medioambiental. En una línea cercana a los planteamientos de Zambrano, agradezco a J, Moreno la referencia a los estudios de Richard Sennet, Flesh and Stone: The Body And The City In Western Civilization, Norton New York, 1994; Building and Dwelling: Ethics for the City, Farrar, Straus and Giroux New York, 2018. Véase también, de reciente aparición: I. CHInchilla, La ciudad de los cuidados, Los Libros de la Catarata, Madrid 2020

50 Con actualización bibliográfica posterior. 